\title{
UJI EFEKTIVITAS EKSTRAK ETANOL KULIT JERUK MANIS (CITRUS SINENSIS) TERHADAP BAKTERI PROPIONIBACTERIUM ACNES
}

\author{
Michiko $^{1}$ Cici Valentina Manalu² Maya Sari Mutia ${ }^{3}$ \\ 1,2,3 Fakultas Kedokteran Universitas Prima Indonesia \\ michiko7274@gmail.com¹ mayasarimutia@unprimdn.ac.id ${ }^{2}$
}

\begin{abstract}
Abstrak
Jeruk manis adalah tanaman yang paling sering dijumpai di Indonesia khususnya Sumatera Utara yang telah diketahui banyak manfaatnya. Buah jeruk manis kaya akan vitamin c dan kulit buah jeruk manis juga mengandung flavonoid dan alkaloid yang bisa menghentikan pertumbuhan bakteri salah satunya bakteri penyebab jerawat yaitu Propionibacterium acnes, kulit jeruk juga berfungsi menghilangkan dan menyembuhkan bintik hitam serta menghaluskan kulit. Penelitian ini bertujuan untuk mulihat daya hambat antibakteri ekstrak etanol kulit jeruk manis terhadap pertumbuhan bakteri Propionibacterium acnes. Penelitian ini adalah penelitian eksperimental dengan menggunakan metode difusi cakram. Hasil penelitian ini didapatkan pengujian ekstrak etanol kulit jeruk manis dengan konsentrasi 50\%, 75\%, dan 100\%, berpengaruh dalam mencegah pertumbuhan bakteri Propionibacterium acnes, sedangkan pada konsentrasi $25 \%$ tidak berpengaruh dalam mencegah pertumbuhan bakteri Propionibacterium acnes.
\end{abstract}

Kata Kunci :Antibakteri, ekstrak etanol kulit jeruk manis (citrus sinensis), propionibacterium acnes

\section{The Effectiveness Test of Citrus Sinensis Peel Exract Again Propionibacterium Acnes}

\begin{abstract}
Sweet orange is one of the most common types of plants that are found in Indonesia, especially in North Sumatra, which is many known its benefits. Sweet orange fruit is high of vitamin C, and the peel of sweet orange also contains flavonoids and alkaloids which can causes acne, namely Propionibacterium acnes. Orange peel also functions to eliminate, cure dark spots and smooth the skin. The aim of this study is to determine the antibacterial inhibition of sweet orange peel ethanol extract on the growth of Propionibacterium acnes. This research is an experimental study using the disc diffusion method. The result of this study were obtained by testing the ethanol extract of sweet orange peel with concentrations of $50 \%, 75 \%$, and $100 \%$ have influenced the inhibitions of Propionibacterium acnes growth, while at $25 \%$ concentration have not influenced in inhibiting the Propionibacterium acnes.
\end{abstract}

Keywords : Antibacterial, ethanol exract of sweet orange peel. Propionibacterium acnes 


\section{PENDAHULUAN}

Jerawat (acne vulgaris) merupakan suatu penyakit inflamasi kronik yang berasal dari unit pilosebaseus yang terlihat dengan terbentuknya komedo, papula, pustula, nodul, kista, dan skar.Jerawat sering timbul di area kulit wajah, leher, dada dan punggung. Jerawat cukup merisaukan karena dapat menurunkan kepercayaan diri, terutama pada orang yang peduli akan penampilan walaupun tidak berdampak fatal ${ }^{1}$.

Catatan studi dermatologi kosmetika Indonesia menunjukkan yaitu terdapat $60 \%$ penderita jerawat pada tahun 2006 dan 80\% pada tahun 2007. Perbandingan penderita penyakit jerawat di negara maju maupun berkembang,lebih tinggi pada wanita dibandingkan pria, dengan rata-rata puncak kejadian pada usia 15 tahun $^{3}$.

$P$. acnes dan S.epidermidis adalah bakteri yang berperan dalam pembentukan jerawat yang merupakan anggota flora kulit dan selaput lendir manusia ${ }^{2}$. Propionibacterium acnes termasuk salah satu bakteri anaerob yang ditemukan pada kulit, tumbuh secara lambat dan bersifat gram positif.Komedo terbentuk dari saluran permukaan kulit yang mengeluarkan sebum yang menggumpal dan tersumbat dan berkembang menjadi inflamasi dan berubah menjadi jerawat jika terinfeksi oleh bakteri.

Gliserol dalam sebum digunakan bakteri ini sebagai nutrisi dan membentuk asam lemak bebas yang dapat menyebabkan timbulnya inflamasi berupa pustula dan papula pada kulit ini merupakan salah satu reaksi untuk mengeluarkan enzim yang dapat merusak dinding folikel rambut. Jerawat dapat berkembang menjadi nodular cystic acnes pada beberapa orang yang ditandai dengan adanya nodula, dan jika ditemui nanah pada lesi kulit dapat meninggalkan bekas luka yang permanen pada saat sembuh $^{12}$.

Selama 30 tahun terakhir berbagai antibiotik telah digunakan sebagai pengobatan efektif pada acne vulgaris.Namun penggunaannya mulai diragukan jika dikonsumsi jangka panjang.

Menurut Utami (2012), salah satu penyebab resistensi penggunaan antibiotik yaitu karena penggunaannya yang sering kali berlebih. Oleh karena itu diperlukan pemanfaatan tanaman yang mengandung antibakteri alami ${ }^{18}$. Salah satunya yaitu kulit jeruk manis yang diketahui berperan sebagai antibakteri karena mengandung senyawa antibakteri berupa alkaloid dan flavonoid.

\section{METODE}

Jenis rancangan penelitian

Penelitian ini menggunakan penelitian eksperimen laboratorik dengan menggunakan difusi cakram dengan rancangan Posttest Only Control Group Designuntuk melihat efektivitas ekstrak etanol kulit Jeruk Manis (Citrus sinensis) terhadap bakteri Propionibacterium acnes.

Waktu penelitian ini dimulai pada bulan Agustus 2019 - September 2019.Penelitian ini dilakukan di Laboratorium Fakultas Matematika dan Ilmu Pengetahuan Alam Universitas Sumatera Utara dan Laboratorium Mikrobiologi Fakultas Kedokteran Universitas Prima Indonesia.

Sampel yang digunakan pada penelitian ini adalah kulit jeruk manis (Citrus sinensis) berupa serbuk simplisia kering kulit jeruk manis yang didapatkan di daerah Sambu Kota Medan serta biakan murni dari bakteri Propionibacterium acnes.

\section{Cara kerja}

Alat dan benda yang akan dipakai harus diatur dengan rapi saat hendak dimasukkan ke dalam autoclave sehingga semua bagian alat dapat terkena uap secara merata dan juga menyeluruh dengan menggunakan tekanan sebesar $1,5 \mathrm{~kg} / \mathrm{cm}^{2}$ pada suhu 121C selama 20 menit menggunakan autoclave. Untuk mencegah terjadinya rekontaminasi setelah keluar dari autoclave alat dan benda harus dibungkus menggunakan plastic kaca dan juga diikat.

Kulit Jeruk Manis (Citrus sinensis) yang digunakan didapatkan dari daerah Kota Medan Jalan Sentral Pasar. Pembuatan sampel memiliki beberapa proses yaitu dimulai dari pencucian, pengupasan, hingga pengeringan. Pertama, kulit jeruk manis sebanyak $5 \mathrm{~kg}$ dicuci dibawah air mengalir hingga bersih, kemudian dikupas.

Kedua, kulit jeruk manis dipotong dadu lalu dijemur selama 4 hari pada suhu ruangan hingga warna kulit jeruk berwarna kuning kecoklatan.

Ketiga, kulit jeruk manis yang sudah kering dihaluskan dengan menggunakan blender. Pembuatan ekstrak kulit jeruk manis, dilakukan menggunakan metode maserasi yaitu dengan merendam serbuk kulit jeruk manis menggunakan etanol 96\% dengan takaran 10 kali lebih banyak dari berat bubuk halus kulit jeruk manis, dan dilakukan sebanyak 3 kali penyaringan menggunakan saring.

Hasil dari maserasi lalu dimasukkan kedalam rotary evaporator selama kurang lebih 3 jam untuk memisahkan etanol dari ekstrak sampai menjadi hampir kental.

Ekstrak kemudian dicampur dengan alkohol 96\% agar diperoleh konsentrasi yang 
dibutuhkan.Dalam penelitian ini konsentrasi yang digunakan yaitu $25 \%, 50 \%, 75 \%$, dan $100 \%$.

Rumus pengenceran konsentrasi $=\times 100 \%$

Selanjutnya dilakukan pembuatan biakan bakteri yang bertujuan memperbanyak jumlah bakteri yang akan digunakan. Hal ini dilakukan dengan menginokulasikan 1 ose biakan murni bakteri $P$. acnes dari agar kedalam media nutrient broth yang kemudian diinkubasi pada suhu 37C selama 24 jam.

Media yang digunakan untuk bakteri P.acnes ini adalah media cair yaitu Nutrient Agar (NA). Untuk membuat media NA ini, sebanyak 12 gram dalam 270 ml etanol 96\% kemudian media Nutrient Agar (NA) dimasukkan kedalam Erlenmayer ukuran $500 \mathrm{ml}$.

Media yang telah berisi Nutrient Agar (NA) dipanaskan dengan menggunakan hotplate dan dihomogenkan dengan stirrer hingga larut dengan sempurna. Kemudian Erlenmayer ditutup menggunakan aluminium foil. Kemudian media disterilkan pada suhu $121 \mathrm{C}$ selama 20 menit.

Pada tahap terakhir dilakukan pengujian sensitivitas dengan beberapa cara: Pertama, usapkan bakteri ke media NA dengan menggunakan cotton swab, diamkan selama 10-15 menit. Lalu letakkan dan rendam blank disk kedalam masing-masing konsentrasi ekstrak kulit jeruk manis. Kemudian letakkan pada permukaan media agar yang berisi bakteri dengan sedikit menekan menggunakan pinset.Setelah itu, inkubasi dalam suhu 37C selam akurang lebih 48 jam.Terakhir, periksa dan ukur zona hambat atau zona bening yang terbentuk menggunakan penggaris.

\section{HASIL}

Diameter Zona Hambat Kulit Jeruk Manis (Citrus sinensis) terhadap bakteri Propionibacterium acnes.

Efektivitas antimikroba kulit jeruk manis (Citrus sinensis) terhadap bakteri Propionibacterium acnes ditunjukkan dengan adanya zona hambat atau zona bening disekeliling kertas cakram. Diameter zona hambat diukur dengan menggunakan jangka sorong dengan konsentrasi 25\%, 50\%, 75\%, dan $100 \%$ didapat zona hambat seperti tabel dan gambar dibawah ini :

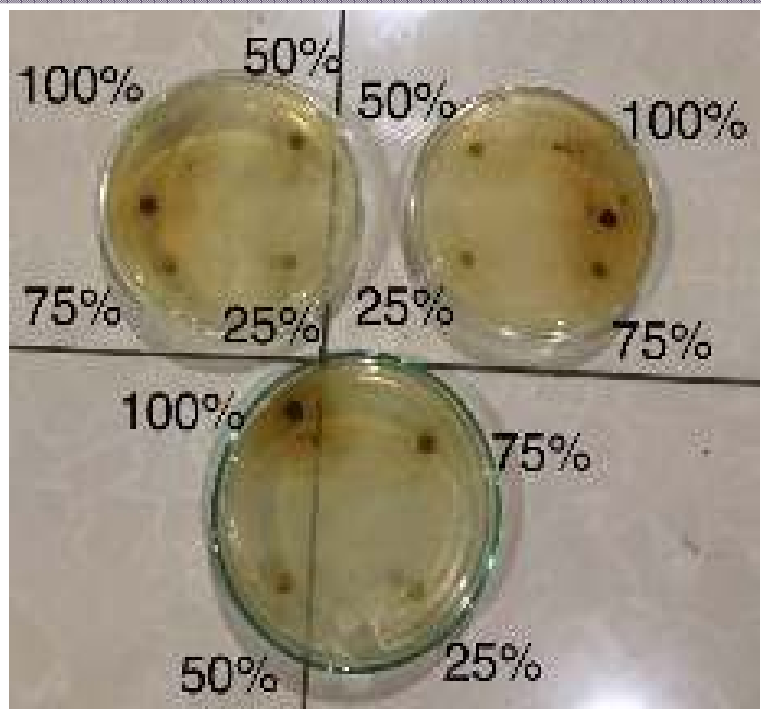

Gambar 1.Pengulangan 1, 2, dan 3 Dengan Konsentrasi 25\%, 50\%, 75\%, dan100\%.

\begin{tabular}{ccccc}
\hline $\begin{array}{c}\text { Percoba } \\
\text { an }\end{array}$ & $\mathbf{1 0 0 \%}$ & $\mathbf{7 5 \%}$ & $\mathbf{5 0 \%}$ & $\mathbf{2 5 \%}$ \\
\hline 1. & 28,7 & 16,5 & 11,1 & 0,00 \\
& $\mathrm{~mm}$ & $\mathrm{~mm}$ & $\mathrm{~mm}$ & $\mathrm{~mm}$ \\
2. & 26,8 & 15,1 & 11,3 & 0,00 \\
& $\mathrm{~mm}$ & $\mathrm{~mm}$ & $\mathrm{~mm}$ & $\mathrm{~mm}$ \\
3. & 23,4 & 15,1 & 8,3 & 0,00 \\
& $\mathrm{~mm}$ & $\mathrm{~mm}$ & $\mathrm{~mm}$ & $\mathrm{~mm}$ \\
\hline $\begin{array}{c}\text { Rata- } \\
\text { rata }\end{array}$ & $\mathbf{1 5 , 5 7}$ & $\mathbf{1 5 , 5 7}$ & $\mathbf{1 0 , 2 3}$ & $\mathbf{0 , 0 0}$ \\
$\begin{array}{c}\text { zona } \\
\text { hambat }\end{array}$ & & $\mathbf{m m}$ & $\mathbf{m m}$ & $\mathbf{m m}$ \\
\hline
\end{tabular}

Tabel 1. Kasil Pengukuran Zona Hambat Kulit Jeruk Manis (Citrus sinensis).

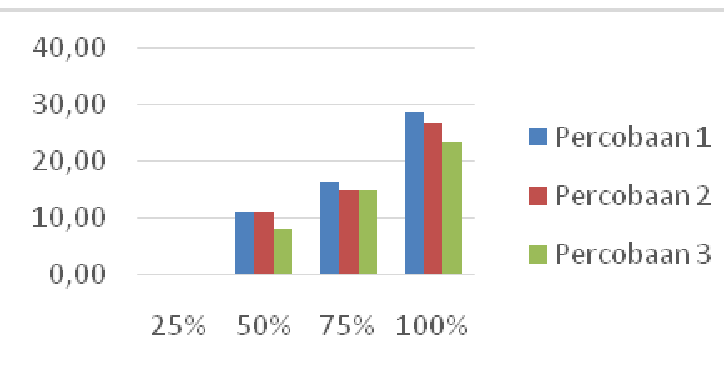

Gambar 2. Diagram Zona Hambat Ekstrak Etanol Kulit Jeruk Manis (Citrus Sinensis) Terhadap Bakteri Propionibacterium Acnes

Berdasarkan penelitian yang telah dilakukan menggunakan ekstrak kulit jeruk manis (Citrus sinensis) terhadap bakteri Propionibacterium acnes pada konsentrasi 25\%, 50\%, 75\%, dan 100\% pada perlakuan U1, U2, dan U3. 
Rata-rata zona hambat pada konsentrasi $25 \%$ sebesar $0,00 \mathrm{~mm}, 50 \%$ sebesar $10,23 \mathrm{~mm}, 75 \%$ sebesar 15,57 mm, dan $100 \%$ sebesar 26,30 mm. Rata-rata zona hambat paling besar pada konsentrasi $100 \%$ yaitu $26,30 \mathrm{~mm}$.

\section{DISKUSI}

\begin{tabular}{cc}
\hline $\begin{array}{c}\text { Rata-rata Diameter Zona } \\
\text { Hambat }\end{array}$ & $\begin{array}{c}\text { Respon Hambatan } \\
\text { Pertumbuhan }\end{array}$ \\
\hline$>20 \mathrm{~mm}$ & Kuat \\
$16-20 \mathrm{~mm}$ & Sedang \\
$11-15 \mathrm{~mm}$ & Lemah \\
$<10 \mathrm{~mm}$ & Tidak Ada \\
\hline
\end{tabular}

Sumber: Rahman Firdaus, 2017

Tabel 2.Klasifikasi zona hambat menurut Greenwood.

Berdasarkan klasifikasi zona hambat Greenwooddiatas diketahui ekstrak etanol kulit jeruk manis pada konsentrasi $25 \%$ tidak mampu mencegah pertumbuhan bakteri, pada konsentrasi 50\% memiliki kemampuan lemah, pada konsentrasi $75 \%$ memiliki kemampuan sedang, dan pada konsentrasi $100 \%$ memiliki kemampuan kuat dalam mencegah pertumbuhan bakteri Propionibacterium Acnes.

Berdasarkan keempat konsentrasi ekstraketanol kulit jeruk manis, konsentrasi 100\% merupakan yang paling efektif dalam mencegah pertumbuhan bakteri Propionibacterium Acnes.Semakin tinggi konsentrasi ekstrak maka laju difusi pada zona hambat akan terbentuk luas ${ }^{14}$.

Hasil skrining fitokimia yang telah dilakukan didapatkan bahwa ekstrak etanol kulit jeruk manis (Citrus sinensis) mengandung alkaloid dan flavonoida yang merupakan senyawa metabolit sekunder. Flavonoid sebagai antimikroba dapat mencegah sintesis asam nukleat, mencegah fungsi membran sel dan mencegah metabolisme energi ${ }^{15}$. Alkaloid sebagai antibakteri dapat mengganggu komponen penyusun peptidoglikan pada sel bakteri, sehingga mengakibatkan kematian sel ${ }^{16}$.

\section{SIMPULAN}

1. Didapatkan bahwa ekstrak kulit jeruk manis (Citrus sinensis) pada konsentrasi 50\%, 75\%, dan $100 \%$ memiliki efektivitas antibakteri dalam mencegah pertumbuhan bakteri Propionibacterium acnes.

2. Didapatkan konsentrasi yang paling efektif daam mencegah bakteri Propionibacterium acnes adalah $100 \%$.

\section{SARAN}

1. Perlu dilakukan penelitian lanjutan tentang efektivitas antibakteri ekstrak kulit jeruk manis (Citrus sinensis) dengan konsentrasi yang berbeda untuk menghambat pertumbuhan bakteri Propionibacterium acnes.

2. Perlu dilakukan penelitian lanjutan dengan menggunakan bagian lainnya dari buah jeruk manis (Citrus sinensis) terhadap bakteri Propionibacterium acnes.

\section{DAFTAR PUSTAKA}

1. Afriyanti, R. N. (2015) 'Akne vulgaris pada remaja', 4, pp. 10-17.

2. Dewi, F. and Kesehatan, F. I. (no date) 'Uji efektivitas minyak atsiri kulit buah jeruk manis '.

3. Meilina, N. E. et al. (no date) 'Farmaka Farmaka', 16, pp. 322-328.

4. Radji M. 2014. Buku Ajar Mikrobiologi. Jakarta: Buku Kedokteran EGC.

5. Suryadi AA. UJI AKTIVITAS ANTIBAKTERI FRAKSI n-HEKSANA, ETIL ASETAT, DAN AIR DARI EKSTRAK ETANOL 70\% DAUN KARI (Murraya koenigii (L.) Spreng) TERHADAP Pseudomonas aeruginosa ATCC 27853 SECARA in vitro. Universitas Setia Budi; 2019.

6. Kandungan A, Pada M, Dari B, Terbarukan SE. Digital Digital Repository Repository Universitas Universitas Jember Jember Digital Digital Repository Repository Universitas Universitas Jember Jember. 2015;

7. Dewi F, Kesehatan Fl. Uji efektivitas minyak atsiri kulit buah jeruk manis.

8. Prasetyo MS, Inoriah E. Pengelolaan Budidaya Tanaman Obat-Obatan (Bahan Simplisia). Badan Penelit Fak UNIB, Bengkulu. 2013;

9. Metode LM. DENGAN PARAMETER KADAR TOTAL SENYAWA ARISTA INDRASWARI K 100040093 FAKULTAS FARMASI. 2008;

10. Rifai MA. Glosarium biologi. Pusat Pembinaan dan Pengembangan Bahasa, Departemen Pendidikan dan Kebudayaan; 1993.

11. No Title. 2019;

12. Radji M. 2018. Buku Ajar Mikrobiologi. Jakarta: Buku Kedokteran EGC

13. Candida, T. (2015) 'AKTIVITAS ANTIJAMUR EKSTRAK TERIPANG BUTOH KELING ( Holothuria leucospilota ) DARI PULAU LEMUKUTAN', 4(4), pp. 7-14.

14. Kumala, S. (2008) 'EFEK ANTIBAKTERI EKSTRAK ETANOL DAUN CENGKEH ( Eugenia aromatic L . )$^{\prime}, 4(2)$, pp. 82-87. 
15. Objek, S. et al. (2019) 'JBIO : JURNAL BIOSAINS ( The Journal of Biosciences )', 5(2), pp. 71-75.

16. Rijayanti, R. P. (2014) 'Program studi pendidikan dokter fakultas kedokteran universitas tanjungpura 2014'.

17. Aida AN, Suswati E. Uji In Vitro Efek Ekstrak Etanol Biji Kakao ( Theobroma cacao ) sebagai Antibakteri terhadap Propionibacterium acnes ( In Vitro Test of the Effect of Cocoa Beans ( Theobroma cacao ) Ethanolic Extract as an Antibacterial against Propionibacterium acnes ). 2016;4(1):127-31.

18. Marselia, S., Wibowo, M. A. and Arreneuz, S. (2015) 'AKTIVITAS ANTIBAKTERI EKSTRAK DAUN SOMA ( Ploiarium alternifolium Melch) TERHADAP Propionibacterium acnes', 4(4) 